\title{
Review
}

\section{A New Frontier in Epilepsy: Novel Antiepileptogenic Drugs}

\author{
Masashi Sasa ${ }^{1,2 *}$ \\ ${ }^{1}$ Emeritus Professor of Hiroshima University \\ ${ }^{2}$ Nagisa Hospital, Nagisaminami-machi 24-31, Hirakata, Osaka 573-1183, Japan
}

Received April 26, 2006

\begin{abstract}
Epilepsy is a hetergenous syndrome characterized by recurrently and repeatedly occurring seizures. Although able to inhibit the epileptic seizures, the currently available antiepileptic drugs (AEDs) have no effects on epileptogenesis. Such AEDs should be classified as drugs against ictogenesis, which are transient events in ion and/or receptor-gated channels related with triggering to evoke seizures. Epileptogenesis involves long-term and histological/biochemical/physiological alterations formed in brain structures over a long period, ranging from months to years. This review focuses on the effects of AEDs on epileptogenesis and novel candidates of antiepileptogenic drugs using a genetically defined epilepsy model animal, the spontaneous epileptic rat (SER).
\end{abstract}

Keywords: epilepsy, ictogenesis, epileptogenesis, antiepileptic drugs, levetiracetam

\section{Introduction}

Epilepsy is a heterogeneous syndrome characterized by recurrent and spontaneous seizures. Approximately $1 \%$ of the population in the world suffers from epilepsy. However, $20 \%-30 \%$ of the patients are refractory to therapies using currently available antiepileptic drugs (AEDs) (1). In addition, continuous medication is necessary even after the seizures have long been suppressed with AED treatments. The most disturbing issue is inability of AEDs to provide a peristent cure because these compounds merely suppress the occurrence of epileptic seizures; that is, AEDs are "antiseizure" but not antiepileptogenic drugs, although they do have certain clinical significance. Therefore, discontinuation of AEDs after a long seizure-free period may risk provoking seizures in patients over time. For instance, it is well known that long-term prophylaxis with phenytoin in patients after brain injury cannot prevent development of epilepsy, even though the drug is capable of inhibiting the occurrence of epileptic seizures (2). Therefore, currently available AEDs should

\footnotetext{
*Corresponding author.

msasa14@sea.plala.or.jp / msmasasa@kb3.so-net.ne.jp

Published online in J-STAGE

DOI: 10.1254/jphs.CPJ06010X
}

be classified as drugs against ictogenesis, which is different from the concept of epileptogenesis (3).

Ictogenesis is a transient and direct event that induces seizures due to excessive discharges from groups of neurons. In short, such discharges are initiated by the sequential opening of the voltage-dependent $\mathrm{Na}^{+}$ channels due to membrane depolarization resulting from $\mathrm{K}^{+}$and/or $\mathrm{Ca}^{2+}$ channel-mediated events or via neurotransmitters and/or activation of ionic glutamate receptors. On the other hand, epileptogenesis involves long-lasting and prolonged histological/biochemical alterations of neuron networks and reorganization of neuronal matrixes, with the process ranging from months to years.

Therefore, ideal AEDs should first control epilepsy itself by preventing formation and development of epileptic foci and/or neutralizing previously established epileptogenesis. The seizure-free condition should then persist after discontinuation of such drug therapies for a certain - the longer the better - period. Second, ideal AEDs should be devoid of adverse effects on physical and mental functions such as cognition. This review focuses on currently available AEDs to prevent epileptogenesis and examines novel candidates of antiepileptogenetic drugs obtained from our recent studies using a genetically defined epilepsy model animal, the spontaneous epileptic rat (SER).

Invited article 


\section{Antiepileptic drugs on epileptogenesis}

\section{Epileptogenesis}

After an epileptic focus has been established, epileptogenesis is gradually and progressively formed. Formation of an epileptic focus requires a long period, which may vary from months to years, before occurrence of the first seizures after the initial injurious event (such as brain injury). After the first seizures, epileptogenesis progresses with more frequent and repeated seizures (Fig. 1) (4). This process in complex partial seizures has been extensively studied (5). The histological changes involved in epileptogenesis include neuronal loss/death and neurogenesis, resulting in reorganization of cell membrane matrixes and formation of axonal/dendritic sprouting (plasiticity) as well as gliosis (5). In the rat-kindling model, subthreshold stimulus repeatedly provokes secondarily generalized seizures, and neuronal loss of up to $20 \%-50 \%$ is observed with an increase in seizures (6). Both necrotic and apoptotic processes contribute to the neuronal loss and damage in this model. However, neurogenesis in kindled animals has been reported to mostly compose of granule cells in the hippocampus (7). In addition, recurrent seizures are known to induce sprouting of mossy fibers of granule cells and hippocampal CA3 region in kindled animals $(8,9)$. Recurrent seizures in kindled animals also induce an increase in expression of glial-fibrillary acidic protein and glial cell hypertrophy /proliferation, resulting in gliosis $(10,11)$. During these events, multivariate gene expression, including nerve growth factor (NGF) and brain-derived nerve factor (BDNF), has been reported to occur in gene-related cascades (12). For example, an initial gene (such as c-fos) induced by the first injury (seizure) supposedly acts on promoter AP-1 to expedite transcription activities of NGF, thereby resulting in facilitation of synaptic transmissions (13) and probable neuronal proliferations. Therefore, down-regulation of inhibitory circuits (GABA neurons connecting to normal or hyperactive excitatory neurons) resulting from the process of neuronal loss and/or up-regulation of an excitatory circuit (such as NMDA neurons) by sprouting and so on may have induced formation of epitogenesis.

Actually, progressive cellular network alterations have been reported in human epileptic brains: these include neuronal loss, axonal sprouting, gliosis, and reorganization of neuronal circuits. Cell loss as well as an increase in Tunel labeling, BAX, and caspase 3 have been found in drug-refractory epileptic brains, suggesting the involvement of programmed cell death $(14,15)$. In addition, serum-specific enolase ( $\gamma$-enolase), a marker of neuronal damage, is also elevated in serum and cerebrospinal fluid after seizures in epileptic patients $(16,17)$. Expression of the polysialylated form of neural-cell adhesion molecules (PSA-NCAM), a marker associated with axonal growth, suggests that axonal sprouting is increased in the dentate gyrus and hippocampal CA1 region in temporal epilepsy (18). These findings in epileptic patients are in accordance with those obtained with experimental animals.

\section{Antiepileptogenetic effects of AEDs}

Antiepileptogenic effects of AEDs are examined in the rat-kindling model and post-status epilepsy model (19). Kindling is a phenomenon where daily deliveries

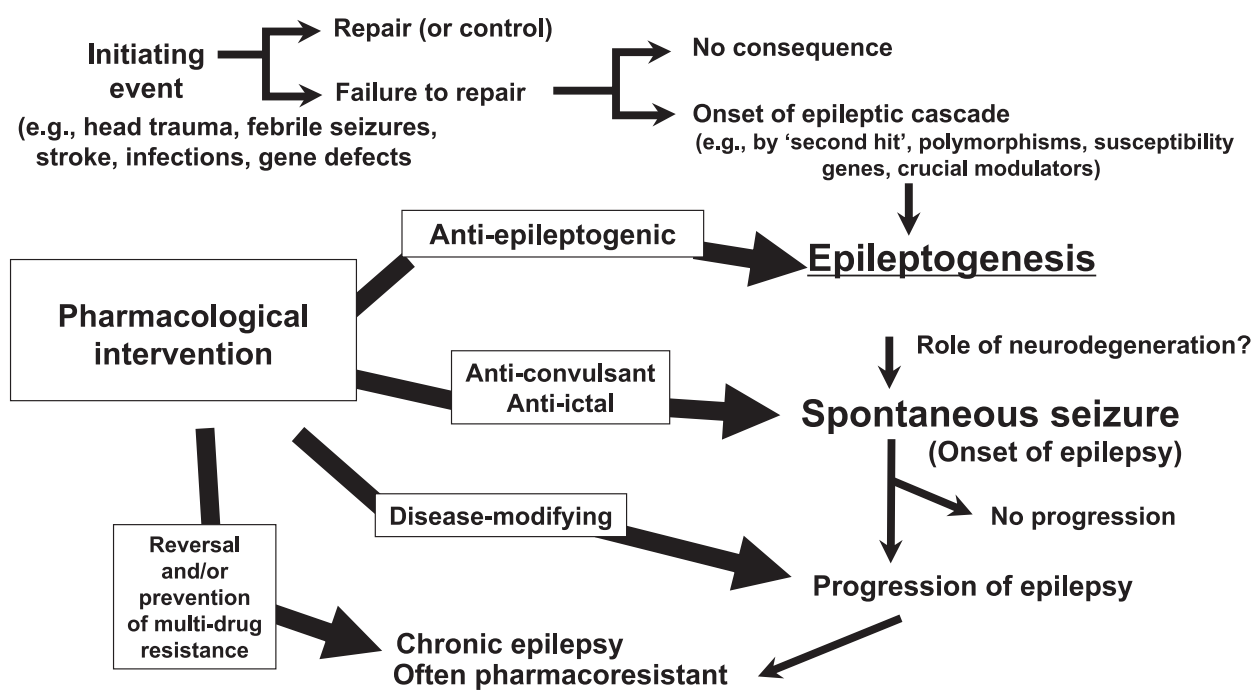

Fig. 1. Development and progression of epilepsy and pharmacological interventions. Modified from ref. 4 with permission from Elsevier (C2002. 


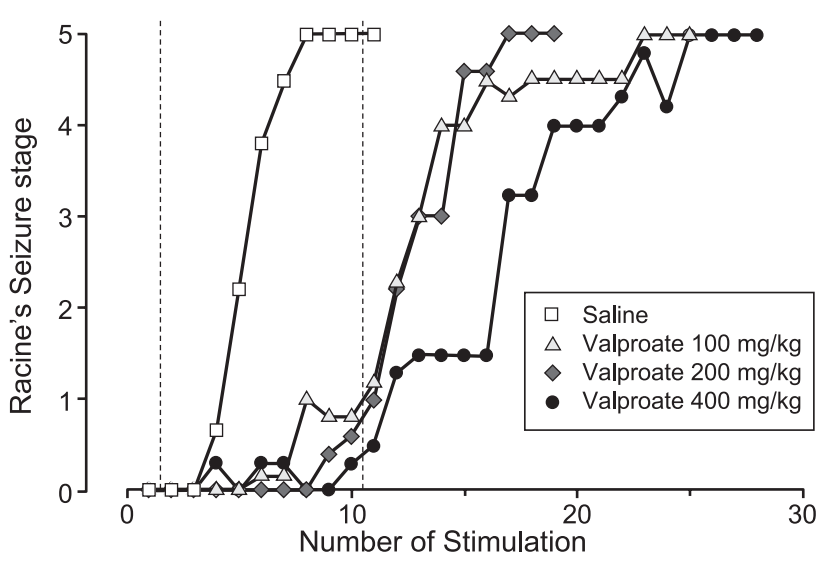

Fig. 2. Effect of valproate on seizure development in kindling rats. Modified from ref. 20 with permission from John Wiley \& Sons, Inc. (C)1991.

of brief subthreshold stimuli to distinct brain areas (such as amygdale or hippocampus) progressively produce convulsive seizures $8-10$ days after initiation of stimuli. The latter model shows spontaneous seizures after a certain silent period following status epileptics induced by kainic acid, pilocarpine, or sustained stimulation of certain brain regions. Concurrent administration of AED with the first stimulation was given to a rat in order to examine whether the drug could inhibit the development of kindling. Note that valproate prolonged the kindling development in a dose-dependent manner (Fig. 2) (20).

In the post-status epilepsy model, antiepileptogenic effects were examined by AED administration immediately after treatment with the status epileptics. Based on the antiepileptogenic effects of AEDs on these modes (Table 1), valproate and topiramate are effective in preventing development of epileptogenesis in both kindling and post-status epilepsy models $(21-23)$. However, in the post-status epilepsy model, valproate is effective in the kainic acid but not the pilocarpine model (24), while topiramate is efficacious in the pilocarpine but not the sustained stimulation model (21). The discrepancy between the valproate and topiramate effects in the kainic acid and pilocarpine and sustained stimulation models might be due to the difference in the mechanism(s) underlying the development of epileptogenesis (21).

In contrast to the results in animal models, anti epileptogenic effects of AEDs have not been observed in clinical studies. According to meta-analyses of controlled trials performed by Temkin et al. (2) and Beghi (25), neither valproate, phenobarbital, phenytoin, diazepam, nor carbamazepine has antiepileptogenic effects (Fig. 3). The discrepancies between experimental and clinical studies on the antiepileptogenic effects are probably due to multifaceted factors; viz., administration methods/routes of AEDs, epilepsy conditions, and use of epilepsy model animals, and so forth. However, it seems most likely that such AEDs have no antiepileptogenic effects or the animal models used are not always appropriate.

\section{Antiepileptogenic effects of levetiracetam (LEV)}

\section{Antiepileptic (anti-seizure) effects of LEV}

LEV is a novel AED available in Europe and USA. This drug has unique pharmacologic properties that differentiate it from currently available AEDs in terms of inhibitory effects that are not observed in maximal electrical stimulation and pentylentetrazole-induced convulsion, albeit effective on seizures in certain chronic animal models such as the kindled and genetic model animals $(26-32)$. In addition, unlike the conventional AEDs, the mechanism underlying the antiepileptic action of LEV does not involve the $\mathrm{Na}^{+}$or $\mathrm{Ca}^{2+}$ channels and/or GABA or glutamate receptors $(33-38)$. The antiepileptic effects include inhibition of the N-type

Table 1. Effects of antiepileptic drugs on development of seizures in kindling and post-status epilepsy models

\begin{tabular}{lccccc}
\hline & \multicolumn{2}{c}{ Kindling model } & & \multicolumn{3}{c}{ Post-status epilepsy models } \\
\cline { 2 - 5 } \cline { 5 - 6 } & kindling & & kainic acid & pilocarpine & $\begin{array}{c}\text { sustained } \\
\text { stimulation }\end{array}$ \\
\hline Valproate & + & & & - & $?$ \\
Phenytoin & - & $?$ & $?$ & $?$ \\
Phenobarbital & + & & & $?$ & $?$ \\
Carbamazepine & - & $?$ & $?$ & $?$ \\
Diazepam & + & $?$ & + & $?$ \\
Topiramate & + & $?$ & - & - \\
Levetiracetam & + & $?$ & & + & $?$ \\
\hline
\end{tabular}

+ and -: effective and not effective in suppressing development of the seizures, respectively; ?: not tested. 


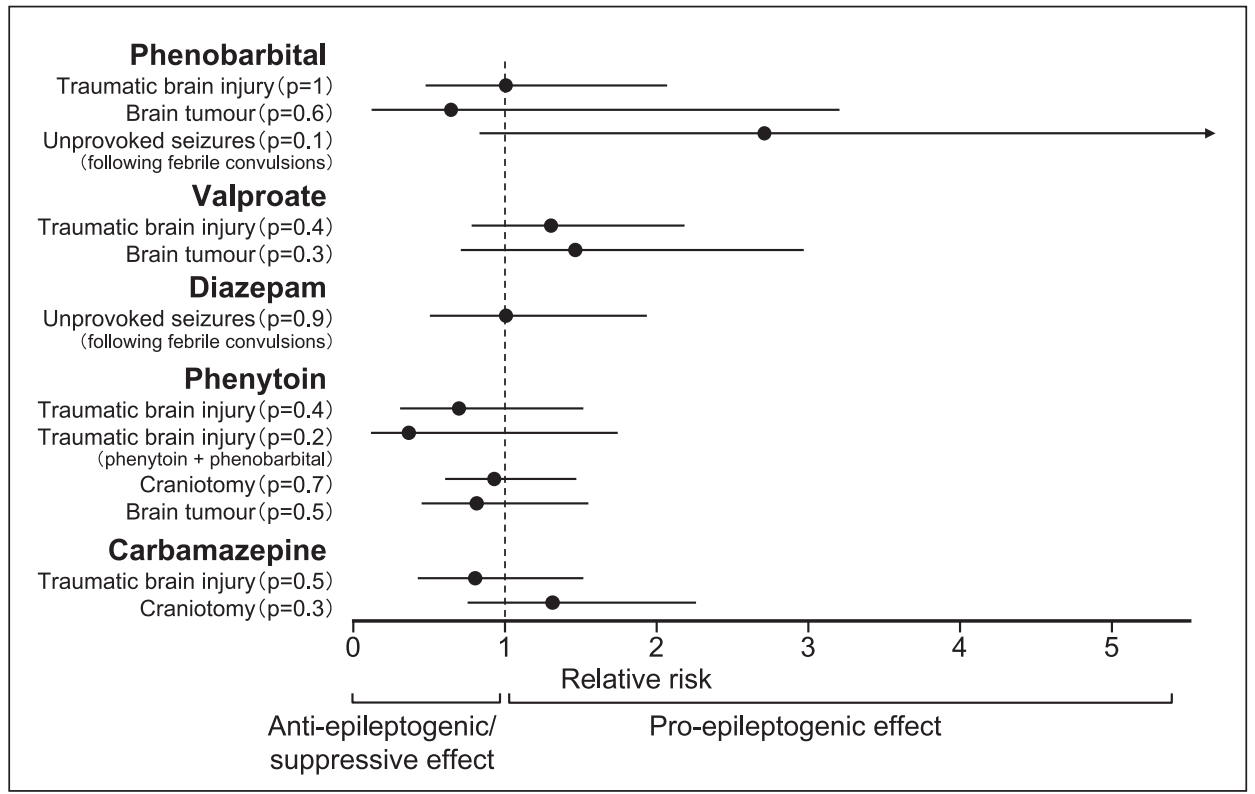

Fig. 3. Meta-analysis of controlled trials using Mantel-Haenszel analysis for relative risk. Relative risk of having at least 1 epileptic seizure. The relative risk is marked by a circle and the line indicates the $95 \%$ confidence interval. Modified from ref. 2 with permission from Adis International Ltd. C2001.
$\mathrm{Ca}^{2+}$ channel $(39,40)$, hypersynchronization of neurons (41), and allosteric modulation of GABA/glycine receptors (37). Recently, SVA2 located on the synaptic vesicle has been found to bind with LEV specifically $(42-44)$. Although the physiological role of SV2 is not fully understood, it supposedly plays an important role in the process of endocytosis, exocytosis, and recycling of neurotransmitters since SVA2 knockout mice show severe convulsions leading to death (45). While it is now unknown whether LEV inhibits or facilitates SVA2 function, binding of LEV to SVA2 may be involved in the antiepileptic effects of LEV, since there is a relationship between binding affinity to human SVA2 and inhibitory effects of LEV on audiogenic seizure of the audiogenic mouse (43). Interestingly, LEV inhibits not only the seizures in kindled animals but also suppresses development of seizure formation during the kindling process, suggesting that the drug elicits antiepileptogenic effects $(46,47)$. However, as described above, antiepileptogenic effects of AEDs observed in certain animal models, such as kindling and post-status epileptic models with pilocarpine, kainic acid, or sustained stimulation, do not coincide well with clinical observations. This divergence in findings is probably due to a long-term latent (preseizure) period after the first kindling in human epilepsy. Therefore, genetically determined epilepsy animals are more suitable for evaluation of antiepileptogenic effects of AEDs.

\section{Spontaneously epileptic rat (SER)}

A double mutant, the spontaneously epileptic rat
(SER: $\mathrm{tm} / \mathrm{tm}, \mathrm{zi} / \mathrm{zi}$ ), is obtained by mating the heterozygous tremor rat $(\mathrm{tm} /+)$ with homozygous zitter rat (zi/zi) $(48,49)$. SER shows both absence-like seizure and tonic convulsions characterized by $5-7 \mathrm{~Hz}$ spikewave-like complexes and fast activities in cortical and hippocampal electroencephalography (EEG) 8 weeks after birth (50). A recent study has demonstrated that SERs lack the gene-encoding aspartoacylase (an enzyme that metabolizes $N$-acetyl-L-aspartate (NAA) into acetate and aspartate) (51) and attractin required for the formation of myelin in nerves (52). The seizures in SERs include abnormal hyperactivities of the L type $\mathrm{Ca}^{2+}$ channels and NAA accumulation attributed to deficiency of the aspartoacylase gene (53). A longlasting depolarization shift accompanying repetitive firings due to $\mathrm{Ca}^{2+}$ channel abnormality and NAA excitation of neurons (by acting on the metabotropic glutamate receptor) has been observed in the hippocampal CA2 neurons in intracellular recording and patch-clamp methods, respectively $(54-56)$.

\section{Antiepileptic effects of LEV in SERs}

A single administration of LEV in SERs inhibits both absence-like seizures and tonic convulsions with an unusually long latency and prolonged effects (57). In addition, when LRV is administered daily in SERs for 5 days, inhibitions of seizures are gradually increased with administration day. The inhibitory effects are unusually long-lasting; suppressive effects on convulsion are still apparent 3 days after the final drug injection, and those on absence-like seizures persist more than 6 days after termination of the administration 


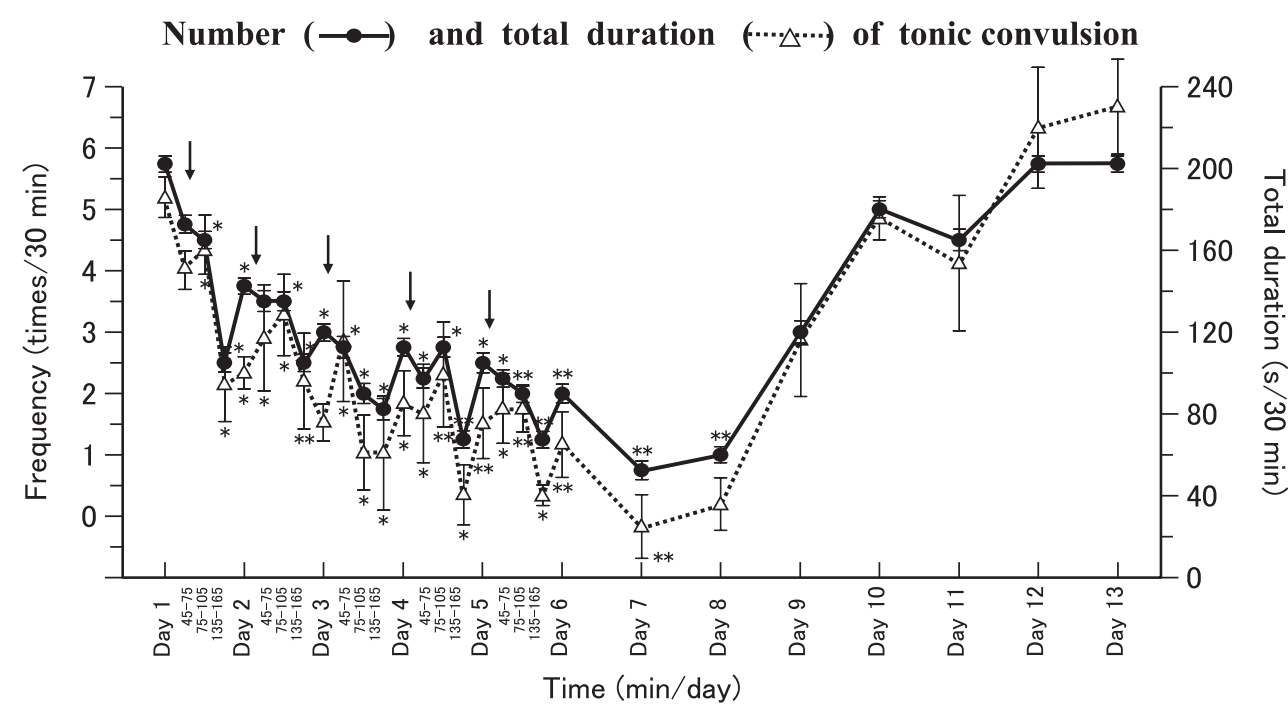

Fig. 4. The time course of the effects of levetiracetam $(80 \mathrm{mg}$ $/ \mathrm{kg} /$ day, i.p.; $\mathrm{n}=4$ ) on number (times/30 $\mathrm{min}$ ) and total duration of tonic convulsions induced by blowing on the face of SER every $5 \mathrm{~min}$ for $30 \mathrm{~min}$. Arrows indicate drug administration. $* P<0.05, \quad * * P<0.01$, compared with the value before administration of levetiracetam. Data are shown as the mean \pm S.E.M. Modified from ref. 57 with permission from Blackwell Publishing (C2005.

Number $(\multimap-$ and total duration $(\cdots, \cdots \cdots)$ of absence-like seizures

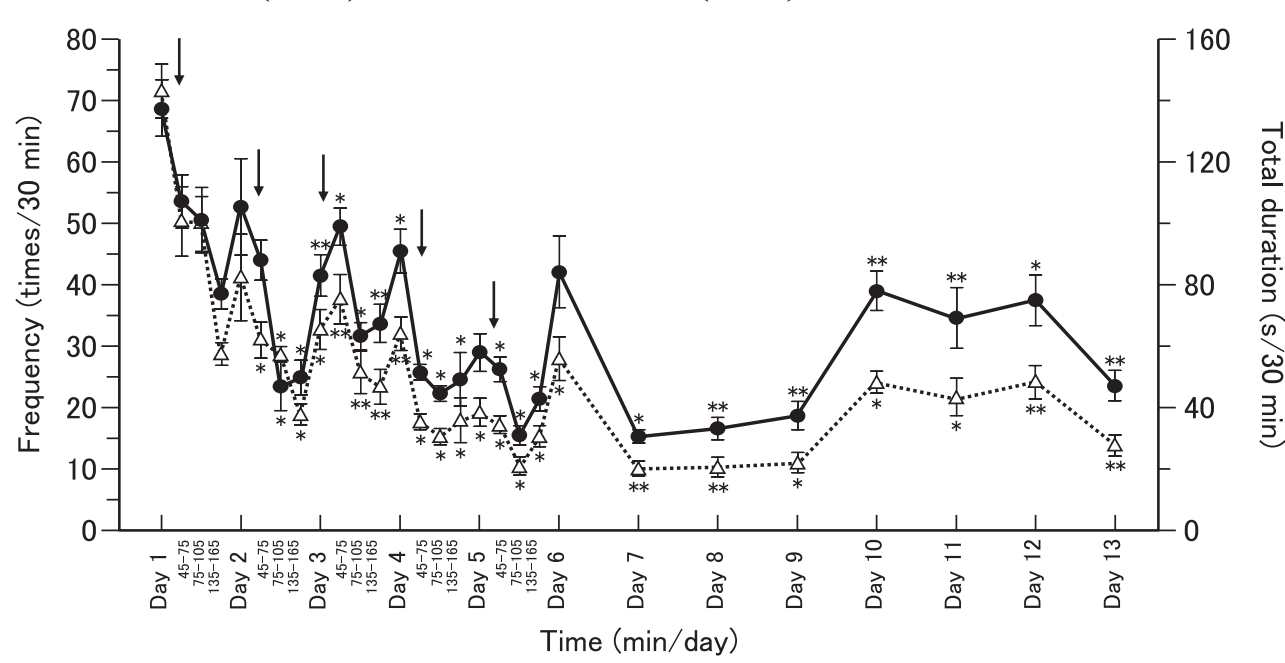

Fig. 5. The time course of the effects of levetiracetam $(80 \mathrm{mg}$ $/ \mathrm{kg} /$ day, i.p.; $\mathrm{n}=4)$ on number (times/30 min) and total duration of absence-like seizures in SER. Arrows indicate drug administration. Absence-like seizures were counted on cortical and hippocampal EEG. $* P<0.05, * * P<0.01$, compared with the value before administration of levetiracetam. Data are shown as the mean \pm S.E.M. Modified from ref. 57 with permission from Blackwell Publishing $\mathbb{C} 2005$.
(Figs. 4 and 5) (57). However, such unusually long effects are not observed in SERs treated with phenytoin, valproate, carbamazepine, or phenobarbital when these AEDs are administered to SER in a manner similar to LEV (Fig. 6) (57). When LEV is intraperitoneally (i.p.) injected in rats, Tmax is attained within $1 \mathrm{~h}$, while plasma $\mathrm{T} 1 / 2$ registers within $3 \mathrm{~h}$ without any drug accumulation in the multiple-administration study (58). Therefore, unusually long-lasting effects of LEV observed in SERs are probably not due to residual drug accumulation, rather induction of certain substances might have inhibited the seizure occurrence. It is therefore rational to assume that LEV suppresses epileptogenesis in SERs. Thus, follow-up experiments further determined whether or not LEV inhibits epileptogenesis in SERs.

\section{Antiepileptogenic effects of LEV in SERs}

Daily i.p. LEV administrations were given to SERs from 4 to 8 weeks of age (seizures usually occur after 8 weeks of age). The frequencies and durations of the convulsive seizures induced by air-puff on the face at 5-min intervals were counted for 30 min weekly from 5 to 13 weeks of age (i.e., 8 weeks after termination of LEV administration). Those of absence-like seizures were counted for $30 \mathrm{~min}$ at 12 and 13 weeks of ages by referring to cortical and hippocampal EEG traces using electrodes implanted at 11 and 12 weeks of age, respectively. The frequencies of convulsive seizures were significantly less in LEV-treated SERs than in physiological saline-treated controls from 9 to 13 weeks of age (Fig. 7) (59). Similarly, the total durations of convulsive seizures were significantly shorter in LEV-treated SERs than controls (59). A significant inhibition of absence- 
Phenytoin (10 mg/kg, n=5)

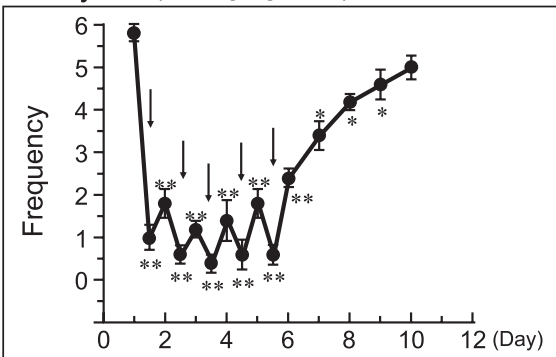

Valproate $(200 \mathrm{mg} / \mathrm{kg}, \mathrm{n}=5)$

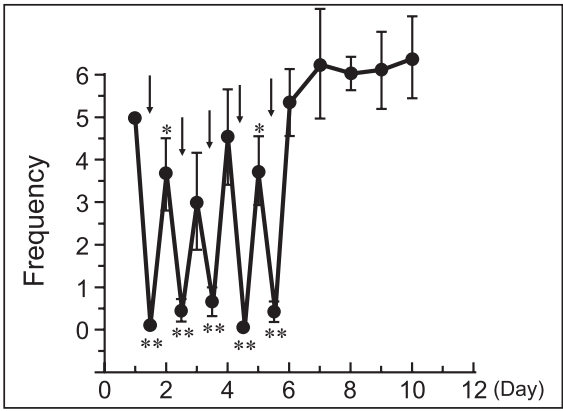

Phenobarbital $(10 \mathrm{mg} / \mathrm{kg}, \mathrm{n}=5)$

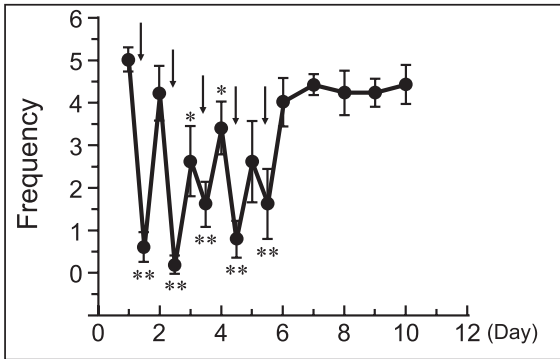

Carbamazepin $(10 \mathrm{mg} / \mathrm{kg}, \mathrm{n}=5)$

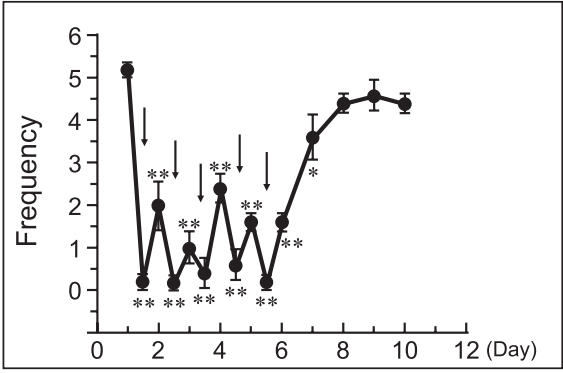

Fig. 6. The effects of phenytoin $(10 \mathrm{mg} / \mathrm{kg} /$ day, i.p.), phenobarbital (10 mg/kg/day, i.p.), valproate (200 $\mathrm{mg} / \mathrm{kg} /$ day, i.p.), and carbamazepine $(10 \mathrm{mg} / \mathrm{kg} /$ day, i.p.) on number of tonic convulsions induced by blowing on the face every $5 \mathrm{~min}$ for $30 \mathrm{~min}$ in SER. The drug effects were measured $45-75 \mathrm{~min}$ after each administration of the drugs and daily $1-5$ days after the final administration. Arrows indicate drug administration. ${ }^{*} P<0.05, * * P<0.01$, compared with the value before administration of phenytoin, phenobarbital, valproate, or carbamazepine. Data are shown as the mean \pm S.E.M. Modified from ref 57 with permission from Blackwell Publishing (C2005.

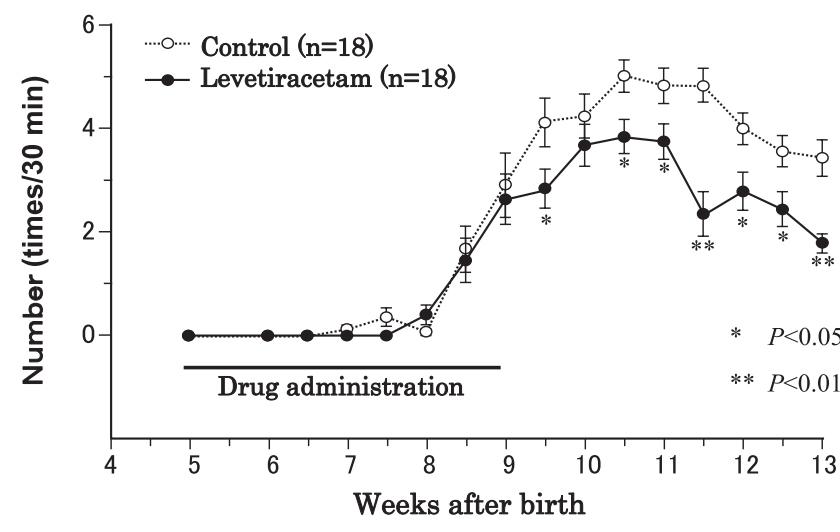

Fig. 7. Effects of chronic levetiracetam administration $(80 \mathrm{mg} / \mathrm{kg}$ /day, i.p. for 4 weeks) during the 'pre-seizure period' (before appearance of the seizures) on number of tonic convulsions induced by blowing on the face every $5 \mathrm{~min}$ for $30 \mathrm{~min}$ in SER. ${ }^{*} P<0.05$, $* * P<0.01$, compared with the control group. Data are shown as the mean \pm S.E.M. Reproduced from ref. 59 with permission from Blackwell Publishing (C2005.

like seizures was observed in LEV-treated SERs compared with controls (59). Recently, similar longlasting antiepileptic effects by LEV have also been observed in genetically absence epilepsy rat from Strasburg (GAERS) (60). Together with our findings, single and repeated administrations of LEV in adult SERs produce unusual long-lasting anti-seizure effects ( $>4$ weeks), which are not considered to be merely due to LEV accumulation in the brain. Rather, the findings suggest that LEV can inhibit epileptogenesis, viz., inhibiting the formation of epileptic foci and/or sup- pressing the development of seizures by inducing certain inhibitory factors through promotion of gene expression. LEV has been reported to prevent changes in levels of BDNF neuropeptide Y mRNA (61) and selectively modify gene expression including neuropeptide $\mathrm{Y}$, $\mathrm{TRH}$, and glial fibrillary acidic protein in kindling rats (62). It is highly possible that long-term treatments with LEV may normalize up-regulation of relevant gene expression induced during the kindling process.

\section{Conclusions and issues relevant with inhibition of epileptogenesis}

For development of novel antiepileptic drugs to suppress epileptogenesis and cure epilepsy itself, it is important to elucidate the mechanism(s) underlying the formation of epileptic foci and development/kindling to epileptic seizures. Conversely, methods using genetic epilepsy model animals such as SER, GAERS, and so on are potentially useful in the search for novel drugs for neutralizing seizure development since candidate drugs can be given to said animals during the pre-seizure period and thereafter over a long period. When a candidate is found to have long-acting anti-seizure effects, elucidation of the underling mechanism(s) may provide a clue to understanding epileptogenesis.

\section{References}

1 Löcsher W. Animal models of intractable epilepsy. Prog Neurobiol. 1997;53:239-258. 
2 Temkin NR, Jarell AD, Anderson GD. Antiepileptogenic agents: How close are we? Drugs. 2001;61:1045-1055.

3 Weaver DF. Epileptogenesis, ictogenesis and the design of future antiepileptic drugs. Can J Neurol Sci. 2003;30:4-7.

4 Löscher W. Current status and future directions in the pharmacotherapy of epilepsy. Trends Pharmacol Sci. 2002;23:113-118.

5 Pitman A, Sutula TP. Is epilepsy a progressive disorder? Process for new therapeutic approaches in temporal lobe epilepsy. Lancet Neurol. 2002;1:173-181.

6 Carvazos JE, Das I, Sutula TP. Neuronal loss induced by kindling in limbic pathways by kindling : evidence for induction of hippocampal sclerosis by repeated brief seizures. J Neurosci. 1994;14:3106-3121.

7 Scott BW, Wang S, Burnham WM, De Boni U, Wojtowicz JM. Kindling-induced neurogenesis in the dendate gyrus of the rat. Neurosci Lett. 1998;248:73-76.

8 Cavazos JE, Golarai G, Sutula TP. Mossy fibre synaptic reorganization induced by kindling: time course of development, progression, and permanence. J Neurosci. 1991;11:2795-2803.

9 Represa A, Salle GL, Ben-Ari Y. Hippocampal plasticity in the kindling model of epilepsy in rats. Neurosci Lett. 1989;99:345350.

10 Hansen A, Jorgensen OS, Bolwig TG, Barry DI. Hippocampal kindling alters the concentration of glial fibrillary acidic protein and other marker proteins in rat brain. Brain Res. 1990;531:307311.

11 Khurgel M, Racine RJ, Ivy GO. Kindling causes changes in the composition of the astrocytic skeleton. Brain Res. 1992;592: 338-342.

12 Hughes PE, Alexi T, Walton M. Activity and injury-dependent expression of inducible transcription factors, growth factors and apotosis related genes within the central nervous system. Prog Neurobiol. 1999;57:421-450.

13 Knipper M, Leung LS, Zhao D, Rylett RJ. Short-term modulation of glutamatergic in adult rat hippocampus by NGF. Neuroreport. 1994;5:2433-2436.

14 Yilmazer-Hanke DM, Wolf HK, ScgeammJ, Elger CE, Wiestler OD, Blumcke I. Subregional pathology of the amygdale complex and entorhinal region in surgical specimen from patients with pharmacoresistant temporal lobe epilepsy. J Neuropathol Exp Neurol. 2000;59:907-920.

15 Henshall DC, Clark RSB, Adelson PD, Chen M, Watkins SC, Simon RP. Alterations in bcl-2 and caspase gene family protein expression in human temporal epilepsy. Neurology. 2000;55: 250-257.

16 Rabinowicz AL, Correale J, Boutros RB, Couldwell WT, Henderson CW, DeGiorgio CM. Neuon-specific enolase is increased after single seizures during inpatient video/EEG monitoring. Epilepsia. 1996;37:122-125.

17 Steinhoff BJ, Tumani H, Otto M. Cisternal S100 protein and neuron-specific enolase are elevated and ste-specific markers in intractable temporal lobe epilepsy. Epilepsy Res. 1999;36:7582.

18 Mikkonen M, Soininen H, Kalviainen R. Remodeling of neuronal circuitries in human temporal epilepsy; increased expression of highly polysialylated neural cell adhesion molecule in the hippocampus and the entorhinal cortex. Ann Neurol. 1998;44:923-934.

19 Pitkanen A, Halonen T. Prevention of epilepsy. Trends Pharmacol Sci. 1998;19:253-255.
20 Silver JM, Shin C, McNamara JO. Antiepileptogenic effects of conventional anticonvulsants in the kindling model of epilepsy. Ann Neurol. 1991;29:356-363.

21 Löscher W. Animal models of epilepsy for the development of antiepileptogenic and disease-modifying drugs. A comparison of the pharmacology of kindling and post-status epilepticus models of temporal lobe epilepsy. Epilepsy Res. 2002;50:105-123.

22 Amano K, Hamada K, Yagi K, Seino M. Antiepileptic effects of topiramate on amygdaloid kindling in rats. Epilepsy Res. 1998;31:123-128.

23 Bolanos AR, Sarkisian M, Yang Y, Hori A, Helmers SL, Mikati $\mathrm{M}$, et al. Comparison of valproate and phenobarbital treatment after status epilepticus in rats. Neurology. 1998;51:41-48.

24 Klitgaard HV, Matagne AC, Vanneste-Goemaere J, Margineanu DG. Effects of prolonged administration of levetiracetam on pilocarpine-induced epileptogenesis in rat. Epilepsia. 2001;42 Suppl 7:114-115.

25 Beghi E. Overview of studies to prevent posttraumatic epilepsy. Epilepsia. 2003;44 Suppl 10:21-26.

26 Klitgaard H. Levetiracetam: the preclinical profile of a new class of antiepileptic drugs? Epilepsia. 2001;42 Suppl 4:13-18.

27 Margineanu DG, Klitgaard H. Levetiracetam: mechanisms of action. In: Levy RH, Mattson RH, Meldrum BS, Perucca E, editors. Antiepileptic drugs. 5th ed. Lippincott Williams \& Wilkins; 2002. p. 419-427.

28 Klitgaard H, Matagne A, Gobert J, Wulfert J. Evidence for a unique profile of levetiracetam in rodent models of seizures and epilepsy. Eur J Pharmacol. 1998;353:191-206.

29 Löscher W, Hönack D. Profile of ucb L059, a novel anticonvulsant drug, in models of partial and generalized epilepsy in mice and rats. Eur J Pharmacol. 1993;232:147-158.

30 Gower A, Hirsch E, Boehrer A, Noyer M, Marescanx C. Effects of levetiracetam, a novel antiepileptic drug, on convulsant activity in two genetic rat models of epilepsy. Epilepsy Res. 1995;22:207-213.

31 Glien M, Brandt C, Potschka H, Löscher W. Effects of the novel antiepileptic drug levetiracetam on spontaneous recurrent seizures in the rat pilocarpine model of temporal lobe epilepsy. Epilepsia. 2002;43:350-357.

32 Sasa M, Yan HD, Ishihara K, Nagayama T, Serikawa T. Is levetiracetam distinct from conventional antiepileptic drugs in antiepileptogenic properties in spontaneous epileptic rats? Epilepsia. 2005;46 Suppl 1:94-95.

33 Zona C, Niespodziany I, Marchetti C, Klitgaard H, Bernardi G, Margineanu DG. Levetiracetam does not modulate neuronal voltage-gated $\mathrm{Na}^{+}$and T-type $\mathrm{Ca}^{2+}$ currents. Seizure. 2001;10: 279-286.

34 Sills GJ, Leach JP, Fraser CM, Forrest G, Patsalos PN, Brodie MJ. Neurochemical studies with the novel anticonvulsant levetiracetam in mouse brain. Eur J Pharmacol. 1997;325:35-40.

35 Fraser CM, Sills GJ, Butler E, Thompson GC, Lindsay K, Duncan R, et al. Effects of valproate, vigabatrin and tiagabin on GABA uptake into human astrocytes cultured from foetal and adult brain tissue. Epilptic Disord. 1999;1:153-157.

36 Tong X, Patsalos PN. A microdialysis study of the novel antiepileptic drug levetiracetam: extracellular pharmacokinetics and effect of taurine in rat brain. Br J Pharmacol. 2001;133:867-874.

37 Rigo JM, Hans G, Nguyen L, Rocher V, Belachew S, Malgrange $\mathrm{B}$, et al. The anti-epileptic drug levetiracetam reverses the inhibition by negative allosteric modulators of neuronal GABA- 
and glycine-gated currents. Br J Pharmacol. 2002;136:659-672.

38 Margineanu DG, Klitgaard H. Levetiracetam has no significant gamma-aminobutyric acid-related effect on paired-pulse interaction in the dentate gyrus of rats. Eur J Pharmacol. 2003;466:255261.

39 Niespodziany I, Klitgaard H, Margineanu DG. Levetiracetam inhibits the high-voltage-activated $\mathrm{Ca}^{2+}$ current in pyramidal neurones of rat hippocampal slices. Neurosci Lett. 2001;306:58.

40 Lukyanetz EA, Shkryl VM, Kostyuk PG. Selective blockade of N-type calcium channels by levetiracetam. Epilepsia. 2002;43: 9-18.

41 Margineanu DG, Klitgaard H. Inhibition of neuronal hypersynchrony in vitro differentiates levetiracetam from classical antiepileptic drugs. Pharmacol Res. 2000;42:281-285.

42 Fuks B, Gillard M, Michel P, Lynch B, Vertongen P, Leprince P, et al. Localization and photoaffinity labeling of the levetiracetam binding site in rat brain and certain cell lines. Eur J Pharmacol. 2003;478:11-19.

43 Lynch BA, Lambeng N, Nocka K, Kensel-Hammes P, Bajjalieh SM, Matagne A, et al. The synaptic vesicle protein SV2A is the binding site for the antiepileptic drug levetiracetam. Proc Natl Acad Sci U S A. 2004;101:9861-9866.

44 Gillard M, Fuks B, Michel P, Vertongen P, Massingham R, Chatelain P, et al. Binding characteristics of $\left[{ }^{3} \mathrm{H}\right]$ ucb 30889 to levetiracetam binding sites in rat brain. Eur $\mathrm{J}$ Pharmacol. 2003;478:1-9.

45 Crowder KM, Gunther JM, Jones TA, Hale BD, Zhang HZ, Peterson MR, et al. Abnormal neurotransmission in mice lacking synaptic vesicle protein 2A (SV2A). Proc Natl Acad Sci U S A. 1999;96:15268-15273.

46 Löscher W, Hönack D, Rundfeldt C. Antiepileptogenic effects of the novel anticonvulsant levetiracetam (ucb L059) in the kindling model of temporal lobe epilepsy. J Pharmacol Exp Ther. 1998;284:474-479.

47 Stratton SC, Large CH, Cox B, Davies G, Hagan RM. Effects of lamotorigine and levetiracetam on seizure development in a rat amygdala kindling model. Epilepsy Res. 2003;53:95-106.

48 Serikawa T, Yamada J. Epileptic seizures in rats homozygous for two mutations, zitter and tremor. J Hered. 1986;77:441-444.

49 Serikawa T, Yamada J, Ujihara H, Ohno Y, Sasa M, Takaori S. Ontogeny of absence-like and tonic seizures in the spontaneously epileptic rat. Laboratory Animals. 1991;25:216-221.

50 Sasa M, Ohno Y, Ujihara H, Fujita Y, Yoshimura M, Takaori S, et al. Effects of antiepileptic drugs on absence-like and tonic seizures in the spontaneously epileptic rat, a double mutant rat. Epilepsia. 1988;29:505-513.

51 Kitada K, Akimitsu T, Shigematsu Y, Kondo A, Maihara T, Yokoi N, et al. Accumulation of N-acetyl-L-aspartate in the brain of the tremor rat, a mutant exhibiting absence-like seizure and spongiform degeneration in the central nervous system. J Neurochem. 2000;74:2512-2519.

52 Kuramoto T, Kitada K, Inui T, Sasaki Y, Ito K, Hase T, et al. Attractin/mahogany/zitter plays a critical role in myelination of the central nervous system. Proc Natl Acad Sci USA. 2001;98:559-564.

53 Amano H, Amano T, Matsubayashi H, Ishihara K, Serikawa T, Sasa M. Enhanced calcium influx in hippocampal CA3 neurons of spontaneously epileptic rats. Epilepsia. 2001;42:345-350.

54 Momiyama T, Ishihara K, Serikawa T, Moritake K, Sasa M. Effects of nicardipine on abnormal excitability of CA3 pyramidal cells in hippocampal slices of spontaneously epileptic rats. Eur J Pharmacol. 1995;280:119-123.

55 Ishihara K, Sasa M, Momiyama T, Ujihara H, Nakamura J, Serikawa $\mathrm{T}$, et al. Abnormal excitability of hippocampal CA3 pyramidal neurons of spontaneously epileptic rats (SER), a double mutant. Exp Neurol. 1993;119:287-290.

56 Yan H-D, Ishihara K, Serikawa T, Sasa M. Activation by Nacetyl-L-aspartate of acutely dissociated hippocampal neurons in rats via metabotropic glutamate receptors. Epilepsia. 2003;44: 1153-1159.

57 Cai Ji-qun, Ishihara K, Nagayama T, Serikawa T, Sasa M. Longlasting anti-epileptic effects of levetiracetam against epileptic seizures in the spontaneously epileptic rat (SER): differentiation of levetiracetam from conventional anti-epileptic drugs. Epilepsia. 2005;46:1362-1370.

58 Patsalos PN. Pharmacokinetic profile of levetiracetam: toward ideal characteristics. Pharmacol Ther. 2000;85:77-85.

59 Yan D-H, Cai Ji-qun, Ishihara K, Nagayama T, Serikawa T, Sasa M. Separation of anti-epileptogenic and anti-seizure effects of levetiracetam in the spontaneously epileptic rat (SER). Epilepsia. 2005;46:1170-1177.

60 Dedeurwaerdere S, Boon P, De Smedt T, Claeys P, Raedt R, Bosman $\mathrm{T}$, et al. Chronic levetiracetam treatment early in life decreases epileptiform events in young GAERS, but does not prevent the expression of spike and wave discharges during adulthood. Seizure. 2005;14:403-411.

61 Husum H, Bolwig TG, Sanchez C, Mathe AA, Hansen SL. Levetiracetam prevents changes in levels of brain-derived neurotropic factor and neuropeptide Y mRNA and of Y1- and Y5-like receptors in the hippocampus of rats undergoing amygdale kindling: implications for antiepileptogenic and mood-stabilizing properties. Epilepsy Behav. 2004;5:204-215.

$62 \mathrm{Gu}$ J, Lynch BA, Anderson D. The antiepileptic drug levetiracetam selectively modifies kindling-induced alterations in gene expression in the temporal lobe of rats. Eur $\mathrm{J}$ Neurosci. 2004;19:334-345. 